\title{
Parameterization of near-bed processes under collinear wave and current flows from a two-phase sheet flow model.
}

\author{
Laurent O. Amoudry ${ }^{*, a}$, Philip L.-F. Liu ${ }^{\mathrm{b}}$ \\ ${ }^{a}$ National Oceanography Centre, Joseph Proudman Building, 6 Brownlow Street, Liverpool, L3 5DA, UK \\ ${ }^{b}$ School of Civil and Environmental Engineering, Cornell University, Ithaca, New York, USA
}

\begin{abstract}
Sediment transport models require appropriate representation of near-bed processes. We aim here to explore the parameterizations of bed shear stress, bed load transport rate and near-bed sediment erosion rate under the sheet flow regime. To that end, we employ a one-dimensional two-phase sheet flow model which is able to resolve the intrawave boundary layer and sediment dynamics at a length scale on the order of the sediment grain. We have conducted 79 numerical simulations to cover a range of collinear wave and current conditions and sediment diameters in the range $210 \mu \mathrm{m}$ to $460 \mu \mathrm{m}$. The numerical results confirm that the intrawave bed shear stress leads the free stream velocity, and we assess an explicit expression relating the phase lead to the maximum velocity, wave period and bed roughness. The numerical sheet flow model is also used to provide estimates for the bed load transport rate and to inspect the near-bed sediment erosion. A common bed load transport rate formulation and two typical reference concentration approaches are assessed. A dependence of the bed load transport rate on the sediment grain diameter is observed and parameterized. Finally, the intrawave near-bed vertical sediment flux is further investigated and related to the time derivative of the bed shear stress.
\end{abstract}

Key words: sediment transport modelling, sheet flows, sediment erosion, bed load transport rate, boundary layer

\section{Introduction}

The coastal, marine and offshore engineering communities require sediment transport models with demonstrable predictive skills, the scales of which usually range from metres to tens of kilometres. Because of limitations on computing resources, small-scale processes can not always be resolved and instead need to be accounted for via subgrid scale modelling. This is particularly pertinent for estimating sediment transport, for which near-bed processes are predominant. Such processes usually occur within the wave boundary layer, which is on the order of $10 \mathrm{~cm}$ and thus may not be resolved. In addition, sediment

\footnotetext{
${ }^{*}$ Corresponding author.

Email addresses: laou@pol.ac.uk (Laurent O. Amoudry), pll3@cornell.edu (Philip L.-F. Liu)

Preprint submitted to Continental Shelf Research

June 4, 2010
} 
transport also involves very near bed processes such as bed load transport rate, which occurs at a scale on the order of a centimetre. Subgrid scale modelling is then required to describe the near-bed hydrodynamics and sediment dynamics, and many different parameterizations have been introduced and implemented. Nevertheless, near-bed results and sediment transport rates are still not very well predicted (e.g., Grasmeijer et al., 2005). Discrepancies between predictions and measurements of the order of a factor of ten are common for near-bed concentration, suspended load transport (Grasmeijer et al., 2005) and bed load transport (Kleinhans and Grasmeijer, 2006). Such disparity in turn results in questionable morphological predictions (Walstra et al., 2005). Further improvements on both transport formulations and on the near-bed description are necessary.

The most common modelling approach is to consider that sediment remains dilute and use an advection-diffusion equation to obtain the suspended sediment concentration. Such an approach is used in models ranging from coastal area models (e.g., Lesser et al., 2004; Warner et al., 2008) to some intrawave sheet flow models (e.g., Ruessink et al., 2009; Hassan and Ribberink, 2010). In coastal models, the settling velocity, the sediment diffusivity and the exchange of sediment between the bed and the suspension (i.e., erosion and deposition) usually all need to be further specified. Sediment bed level changes are tracked by applying the sediment mass conservation between the bed and the suspension: first calculating the bed mass change due to erosion, deposition, and the divergence of the horizontal bed load fluxes, and then translating it into a bed level change. Near-bed processes are not resolved and thus have to be parameterized, usually in a wave-averaged manner. Such formulations need to provide information on bed load transport rate and erosion rate, which in turn requires appropriate description of the bed shear stress. For intrawave models, the near-bed processes may not be entirely resolved and some parameterization may be necessary. Most common is providing a mathematical formulation for the intrawave erosion rate, through a reference concentration for example (e.g., Amoudry et al., 2005; Ruessink et al., 2009; Hassan and Ribberink, 2010).

Such effort, both for intrawave and wave-averaged expressions, has traditionally been pursued through empirical means. But some advanced small-scale local models are now able to fully resolve near-bed sediment transport and could thus be used to gain insight on the parameterizations pertinent to larger scale models. For example, detailed process models are now able to represent very near bed sediment behaviour under the sheet flow regime using descriptions of two-phase sediment fluid interactions (e.g., Dong and Zhang, 2002; Hsu et al., 2004; Li et al., 2008) and granular flow dynamics (e.g., Jenkins and Hanes, 1998; Drake and Calantoni, 2001). Similar two-phase models have been developed for multi-dimensional studies (e.g., Zhao and Fernando, 2007; Amoudry and Liu, 2009), but their applications remain limited to scour problems. Other multi-dimensional models typically aim to resolve complex hydrodynamic processes, such as vortex formation and shedding in oscillatory flows over rippled beds (e.g., Malarkey and Davies, 2002; Zedler and Street, 2006) and coherent vortex structures (Zedler and Street, 
2001; Vittori, 2003), so as to assess their influence on sediment transport.

In spite of the relatively advanced state of process modelling for sediment transport under sheet flow conditions, sucessful models that do not require near-bed empirical parameterizations are still too rarely used as investigative tools. We aim here to discuss the parameterization of near-bed hydrodynamic and sediment processes using small-scale numerical results obtained with a validated two-phase sheet flow model. This model has been introduced in Hsu et al. (2004) and Amoudry et al. (2008) and validated for sand transport under the sheet flow regime in Amoudry et al. (2008). It is based on a two-phase approach that includes a modified $k-\varepsilon$ closure accounting for the influence of the particles on the fluid turbulence, and a modified collisional theory to describe the inter-particle interactions. Common near-bed empirical parameterizations (e.g., bed load transport rate, reference concentration) are not employed and can instead be assessed due to the good predictive ability of the model and the high level of physical description and resolution.

In this paper, we will focus on the bed shear stress, the bed load transport rate and the erosion flux (also called resuspension, or pick-up), which are three of the most important quantities commonly parameterized. We will first describe in further detail the implementation of the two-phase sheet flow model. We then discuss the numerical results and the subsequent parameterizations for the bed shear stress, the bed load transport rate and the erosion rate. In particular, the bed load transport rate is compared to a common semi-empirical formulation and the erosion rate to two widely used formulations for the reference concentration.

\section{Two-phase sheet flow sediment transport modelling}

\subsection{Model description}

The sheet flow model of Hsu et al. (2004) and Amoudry et al. (2008) solves concentration-weighted averaged mass and momentum conservation equations for both a sediment and a fluid phase. Fluid phase stresses are calculated using the turbulent viscosity hypothesis and a $k-\varepsilon$ model that is modified to account for the two-phase approach and for the influence of the sediment particles on the fluid turbulence. Sediment phase stresses are calculated using a modified collisional theory that provides a mathematical description of the particle-particle interactions (see appendix and Amoudry et al. (2008) for more details). Computations are performed from within the sediment bed, in which there is no sediment motion, throughout the bottom boundary layer (see figure 1). The time-dependent location of the bed is thus part of the model's solution and is determined using a Coulomb failure criterion (Hsu et al., 2004).

This two-phase sheet flow model has already been described in detail in Hsu et al. (2004), Amoudry (2008) and Amoudry et al. (2008), and a detailed description is presented in the appendix. It has been validated against a number of independent data sets. Hsu et al. (2004) tested the sheet flow model for relatively 
massive particles against the data of Sumer et al. (1996) for steady flows, and against intrawave sediment velocity and concentration data from Asano (1995) for oscillatory flows. Amoudry et al. (2008) validated the model for sheet flow sand transport against data obtained in oscillatory water tunnels with Conductivity Concentration Meters for intrawave sediment concentration in the sheet layer (Dohmen-Janssen, 1999; O'Donoghue and Wright, 2004) and for sediment velocities and fluxes in the sheet layer (McLean et al., 2001). Data obtained from a boroscopic technique for sediment velocity under steady flows (Dudley, 2007) were also reproduced by the model. Overall, these numerous model-data comparisons demonstrate the good predictive behaviour of the model for near-bed intrawave concentration, velocities and sediment fluxes.

The main characteristic of this model is its ability to represent and fully resolve near-bed sediment dynamics, including the sheet layer and the pick-up layer (layer where concentration is anti-phase with flow velocity), following theoretical physical considerations. In particular, the near-bed gradients can be resolved, and both bed load transport rate and erosion rate are not parameterized but rather are results of the model. Near-bed information can thus be obtained and used to help assess near-bed parameterizations used in other models for the bed shear stress, bed load transport rates, and erosion flux. It differs in that aspect from sheet flow models that use near-bed empirical parameterizations for the reference concentration (e.g., Amoudry et al., 2005; Ruessink et al., 2009; Hassan and Ribberink, 2010) and for the bed load transport rate (e.g., Hassan and Ribberink, 2010). We also believe that it offers more insight on the small-scale physics involved than models that employ an empirical formulation for the sediment phase stresses (e.g., Dong and Zhang, 2002; Li et al., 2008).

However, limitations exist. The two main limiting issues concern the turbulence closure and the collisional granular flow theory used to respectively calculate fluid and sediment stresses. The turbulence closure implemented in Amoudry et al. (2008) reduces to a typical $k-\varepsilon$ model for clear fluid (e.g., Justesen, 1991). Such closure has been found to reproduce the intrawave wave boundary layer dynamics reasonably well, even if some discrepancy in model-data comparisons usually remains in the decelerating stage (Justesen, 1991). Furthermore, turbulent bursts, which have been linked to strong suspension events for fine sand $\left(D_{50}<0.2 \mathrm{~mm}\right)$, cannot be resolved by the ensemble-averaged approach used in the model. Shortcomings for the sediment stress formulations are mainly due to particle-particle interactions not occurring in the collisional regime (Amoudry et al., 2008), which typically happens for slower flows and finer sediments. These issues combine to explain the poor behaviour of the model observed for fine sand.

\subsection{Model implementation}

In this paper, we use this sheet flow model under a number of flow and sediment conditions that remain within the limitations just discussed. The model is implemented in one dimension using a finite-difference discretization with a variable vertical grid size, which has a minimum of $0.3 \mathrm{~mm}$ in the near-bed region. 
The model is driven by a horizontal pressure gradient (Hsu et al., 2004; Hsu and Hanes, 2004) leading to the free stream velocities (fluid velocity $10 \mathrm{~cm}$ above the undisturbed bed location) represented by equation 1 and summarized in table 1. The top boundary condition has been kept as a rigid lid (Hsu et al., 2004) in accordance with laboratory experiments used for model validation. The bottom boundary condition is located within the sediment bed, the concentration is fixed at 0.635 , the velocities are fixed at zero, and the turbulence is determined from a log-law. Other conditions have been tested and found not to impact the results due to the bottom boundary location being within the sediment bed (Amoudry, 2008). Because the model cannot accurately reproduce the initiation of sediment motion, an artificial initial condition is specified (Hsu et al., 2004), following which the concentration decreases linearly with height and the flow is at rest. Computations are then performed with the vertical velocity remaining zero (Hsu et al., 2004) before applying the time-dependent pressure gradient. All simulations were run for 20 wave cycles. The results were always found to reach a quasi-steady state quickly (less than 5 wave cycles) and the last fifteen cycles were used for phase and wave averaging.

A total of 79 arbitrarily chosen cases were simulated (table 1), spanning sediment grains of diameter from $210 \mu \mathrm{m}$ to $460 \mu \mathrm{m}$ and of constant specific gravity $s=2.65$. Flows consisted of combinations of currents and (dominant) waves for which the free stream velocity is prescribed as follows:

$U_{0}(t)=U_{0 c}+U_{01} \cos \frac{2 \pi t}{T}+U_{02} \cos \frac{4 \pi t}{T}$

with $U_{0 c}$ being the current velocity, $U_{01}$ and $U_{02}$ the amplitudes of the first and second wave velocity harmonics (in all cases $U_{01}>U_{02}$ ), and $T$ the wave period. All cases simulated present values of $U_{01} \omega /(s-1) g(\omega \equiv 2 \pi / T)$ below 0.3 , thus corresponding to a quasi-steady regime (Sleath, 1994). Even though several wave periods have been prescribed, little dependence of the results on the period has been observed. Noticeably, cases 6 and 47 correspond to some experiments of Dohmen-Janssen (1999), cases 20 and 76 to experiments of O'Donoghue and Wright (2004), and cases 51 and 52 to the experiments of McLean et al. (2001), which were all used for the model validation in Amoudry et al. (2008).

\section{Bed shear stress}

Near-bed sediment transport parameterizations are commonly expressed in terms of the Shields parameter $\theta$, which is the non-dimensional bed shear stress, $\theta=\tau_{b} /(\rho(s-1) g d)$ where $\tau_{b}$ is the bed shear stress, $\rho$ the fluid density, and $d$ the sediment grain diameter. Appropriate bottom boundary layer models are crucial for obtaining accurate $\theta$ values since vertical resolution will not be sufficient to resolve the near-bed gradients in coastal models. Most bottom boundary layer models use a friction coefficient to relate the bed shear stress to the flow velocity, usually through a quadratic law. In the case of pure currents and velocities evolving on timescales much longer than the numerical time step (e.g., tidal currents), the 
friction coefficient is specified directly or by assuming a logarithmic velocity profile. The later case has been extensively studied in the past decades and was also discussed in Amoudry et al. (2008).

For wave and wave-current bottom boundary layers, hydrodynamic process studies usually find a phase lead of the bed shear stress with respect to the free stream velocity (e.g. Jensen et al., 1989; Guizien et al., 2003) and so do the present results (figures 2 and 3). For large-scale models, the aim is to account for the effects of the oscillatory flow without resolving individual waves. To that end, a common approach is to use again a quadratic friction law for which the wave-current friction coefficient is specified either with an explicit formula (e.g., Madsen, 1994) or with an implicit method (e.g., Grant and Madsen, 1979), and for which the bed roughness may be enhanced by the waves (e.g., Madsen, 1994). For intrawave modelling, quadratic laws are also used (e.g., Ribberink, 1998; Hsu et al., 2006; Gonzalez-Rodriquez and Madsen, 2007). Usually, both a constant friction factor and bed shear stress in phase with the orbital velocity are assumed. However, neglecting the phase lead of the bed shear stress can lead to significant errors (e.g., Nielsen and Callaghan, 2003) and the constant friction factor is contrary to a simple conceptual model of the intrawave bed shear stress (Gonzalez-Rodriquez and Madsen, 2007). This in turn requires better parameterization of both the phase lead and friction factor for intrawave modelling (e.g., Madsen, 1994; Gonzalez-Rodriquez and Madsen, 2007).

The bed shear stress is calculated for the sheet flow simulations as the total shear stress at the undisturbed bed level (i.e., $z=0$ and bed level for no flow condition). Five examples of the intrawave bed shear stress are shown in figure 2. The form of the intrawave bed shear stress is important for developing simple wave-averaged models, and while it can reasonably be approximated by a decomposition into mean and first two sinusoidal harmonics (i.e., $\theta(t)=\theta_{c}+\theta_{w 1} \cos (\omega t)+\theta_{w 2} \cos (2 \omega t)$ ) for the example in the second panel of figure 2 , it is generally not the case, as illustrated by the other examples in figure 2.

The bed shear stress is found to have a phase lead $\left(\phi_{\tau}\right)$ mostly in the range of 10 to 15 degrees with respect to the free stream velocity (figure 3) and we observe a dependence on the wave parameters. Such a phase shift can for example be approximated from the results of a wave-current boundary layer model (Madsen, 1994), which gives $\phi_{\tau}$ expressed in radians:

$$
\begin{gathered}
\phi_{\tau}=\frac{\pi}{60}\left[11-2.0 \log _{10}\left(\frac{U_{0 \max }}{k_{N} \omega}\right)\right] \\
\text { for } \quad 0.2<\frac{U_{0 \max }}{k_{N} \omega}<10^{3}
\end{gathered}
$$

where $k_{N}$ is the equivalent roughness. Our numerical results provide an estimate of the phase lead, but the roughness is a priori unknown. One can then use equation 2 to obtain $k_{N}$ values from the phase lead. This yields roughnesses in the range $d<k_{N}<10 d$, which is consistent with the previous findings of Wiberg and Rubin (1989), Sumer et al. (1996), and Amoudry et al. (2008). One can also focus on the inverse problem and assess equation 2 in combination with a roughness predictor. For example, the numerical results are plotted in figure 3 using a roughness value calculated following Wiberg and Rubin (1989). Interestingly, 
equation 2 represents relatively well the phase lead from the numerical simulations, including for the cases such that $U_{0 \max } / k_{N} \omega>10^{3}$.

\section{Bed load transport rate}

Sediment transport is supported by two main mechanisms: interactions between sediment grains and agitation of fluid turbulence. Bed load is usually defined as the region where sediment motions and suspension are dominated by particle-particle interactions. Conversely, the primary mechanism in the suspended load is turbulent suspension, which is due to the fluid agitation. As mentioned in Amoudry et al. (2008), both the sediment stress gradient, which mathematically represents here the suspension term due to inter-particle interactions, and the fluid turbulent suspension term can be explicitly calculated from the numerical results (see appendix for more details). A comparison of their relative importance then enables distinction between bed load and suspended load and leads to information on the bed load layer (figure 4). We choose to define the bed load in our results as the region for which the sediment stress gradient is greater than the turbulent suspension. This corresponds to the layers as depicted in figure 4 where the grey dashed line marks the limit between suspended load and bed load. Although continuous, the transition from bed load to suspended load is observed to be rather sharp and thus provides reasonable precision on the bed load layer (figure 4). In turn, such information helps determine various near-bed quantities such as the bed load transport rate, for which we expect reasonable predictions given the favourable model-data comparisons for near-bed sediment fluxes in Amoudry et al. (2008).

\subsection{Current approaches}

Accurately predicting sediment transport rates has been an important issue for several decades. Bed load transport rates have been measured experimentally using bed load traps, leading to empirical formulae (e.g., Meyer-Peter and Müller, 1948; Wilson, 1966; Ribberink, 1998). The most common formulations relate the non-dimensional transport rate $\Phi_{B}$ to the Shields parameter as:

$\Phi_{B}= \begin{cases}m \theta^{n}\left(\theta-\theta_{c}\right)^{p} & \theta \geq \theta_{c} \\ 0 & \theta<\theta_{c}\end{cases}$

where $\theta_{c}$ is the critical Shields parameter for incipient motion, $m$ is usually taken as a constant and $n+p \approx 1.5$ (table 2 ). While such a relationship was first developed for steady flows, it has since been extended to time-dependent transport rates in wave-current combinations as long as a quasi-steady approach is valid (Ribberink, 1998). In the case of coastal area models for which the wave oscillations are not resolved, the net transport rate is related to some measure of the bed shear stress over a wave period. For example, Soulsby and Damgaard (2005) integrated a vectorial time-dependent formula (equation 3) 
over the wave period and expressed the bed load transport rate in terms of the mean and the amplitudes of the first and second harmonics of the bed shear stress.

A crucial and problematic issue in experimental studies is the distinction between bed load and suspended load. Measurements of bed load transport rates usually rely on the assumption that the trap only catches sediment transported as bed load. While this may be reasonable for massive particles unlikely to get suspended (as in Meyer-Peter and Müller (1948) for example), it will lead to an overestimation of the bed load transport rate for finer particles which are transported as suspended load in a significant manner (e.g., Hassan and Ribberink, 2010). In addition, sediment traps can induce important flow modifications and scour leading to measurement uncertainty. In contrast, the sheet flow model provides a new method for which a clear distinction between bed load and suspended load can be made.

\subsection{Numerical predictions}

Numerical results for the bed load transport rate and the empirical formula (equation 3 used in a quasi-steady sense) are compared within a wave period in figure 5 for the same five examples as in figure 2 . For the purely sinusoidal case, the comparison is relatively good throughout the wave period. For the other cases, the comparison is in general reasonable during the positive cycle (especially in terms of the net half cycle transport rate) and improves with higher stresses, but there is a recurring discrepancy for the negative half cycle. This is consistent with the lack of accuracy of the sediment flux predictions during the negative half cycle observed in Amoudry et al. (2008). Such discrepancy is not seen in the top case of figure 5 and is also found to increase with decreasing particle diameters. We thus believe that it is caused by the limitations of the collisional theory for weak forcing and small particles. In turn, this disparity will lead to a positive bias for the net bed load sediment transport obtained from the numerical sheet flow results and will also cause higher errors for the net values in the Stokes waves cases simulated.

The wave-averaged expressions of Soulsby and Damgaard (2005) allow for easy implementation of bed load calculation in large-scale sediment transport models under a fairly wide range of conditions and we choose to compare this semi-empirical model to the numerical results obtained with the model of Amoudry et al. (2008) (figure 6). The circles represent cases for sinusoidal waves superposed on a current, the squares represent cases for 2nd-order Stokes waves without any current, and the diamonds are for 2nd-order Stokes waves superposed on a current. This last type of flow is of particular interest given the lack of experimental data (Soulsby and Damgaard, 2005). Different grain diameters are represented by symbols of different colour. The general agreement can be considered as quite good as most points fall within a factor two of perfect agreement. Following the previous discussion on the respective accuracies of the numerical and experimental methods, we expect a relative overestimation from the numerical results (points above the diagonal) for 2nd-order Stokes waves and a relative overprediction from the semi-empirical formulations (points under the diagonal) for smaller sediment diameter, both of which are indeed observed. 


\subsection{Improved parameterization}

While there is a somewhat general agreement concerning the functional form of the bed load transport rate, there have been a number of different values proposed for $m$ as shown in table 2. Detailed inspection of figure 6 reveals that transport rates for the smaller sediments generally are below the perfect agreement line while transport rates for the larger sediments are above. In a simple attempt to improve the bed load predictions, we calculated for each sediment diameter the best value for $m$ by minimizing the root-mean-square error between numerical results and the semi-empirical equations. We neglected the cases for second-order Stokes wave forcing for which the numerical model is expected to perform worse. A distinct dependence on the sediment diameter is obtained and illustrated in figure 7 where a factor two difference is observed between small and large diameters. With the exception of the largest diameter, the proportionality factor is found to decrease with decreasing grain diameter. This is consistent with suspension criteria (e.g., Bagnold, 1966), which can be seen as expressing that at identical Shields parameter, large particles are transported as bed load, while fine particles are transported as suspended load (see also figure 1 of Amoudry et al. (2008)). Mathematically, this behaviour can be well approximated by the following relationship

$m=17.75 \times\left[1-\frac{\exp \left(-\exp \left(\frac{R_{p}-15}{10}\right)\right)}{\exp \left(-\exp \left(-\frac{15}{10}\right)\right)}\right]$

where $R_{p}=D_{50} \sqrt{(s-1) g D_{50}} / \nu$ is the fall parameter. The positive bias of the numerical predictions is also observed in the values numerically calculated for the larger diameters and the factor 17.75 in equation 4. The improvement made by adding equation 4 to the formulation of Soulsby and Damgaard (2005) is shown in figure 8 . There is indeed a better agreement when using equation 4 , in particular for the larger transport rates. The root-mean-square error between numerical results and the parameterization diminishes from a factor 2 to a factor 1.86 when implementing equation 4 . While this may seem modest, the improvement is clearer for non-dimensional transport rate over 0.2 , the error diminishes from a factor 2.04 to a factor 1.85 .

\section{Erosion rate}

The net bottom boundary sediment flux is commonly divided in an upward part (erosion, $E$ ) that represents the exchange of sediment from the bed to the flow and a downward part due to gravitational settling (deposition, D). A numerical erosion flux can thus be derived from collocated and simultaneous numerical results of vertical sediment flux and sediment concentration, which in turn enables assessment of diverse parameterizations. Both $E$ and $D$ hereafter will be taken to have the dimension of a velocity, corresponding to a sediment mass flux divided by the sediment density. 


\subsection{Current approaches}

The main method employed to express erosion of non-cohesive sediments in terms of flow and sediment parameters uses the assumption that the disequilibrium introduced by the unsteadiness remains mild, and that the erosion flux is equal to the entrainment rate under equilibrium conditions (Garcia and Parker, 1991). The erosion flux is then related to a reference concentration value through the settling velocity, i.e. $E=c_{r e f} W_{s}$ (e.g., Harris and Wiberg, 2001; Lesser et al., 2004). This approach usually provides a formula for the reference concentration at some reference level, i.e. $C_{r e f}$ at $z_{r e f}$, where both $C_{r e f}$ and $z_{r e f}$ may be functions of flow and sediment parameters such as the Shields parameter (non dimensional bed shear stress), the sediment specific gravity and the sediment diameter. The deposition is then calculated using the non-equilibrium concentration $D=c_{b} W_{s}$, where $c_{b}$ is the actual bottom concentration. Many reference concentration relationships have been introduced and the most commonly used formulae in large-scale models remain that of Smith and McLean (1977), van Rijn (1984) (updated most recently to van Rijn (2007)) and Zyserman and Fredsoe (1994).

We explicitly introduce the formulations of Zyserman and Fredsoe (1994) and van Rijn (2007) since they are used in comparisons with numerical results in the following section. The expression of Zyserman and Fredsoe (1994) relates the reference concentration to the Shields parameter at an elevation of two grain diameters above the bed:

$c_{\text {ref }}=\frac{0.331(\theta-0.045)^{1.75}}{1+\frac{0.331}{0.46}(\theta-0.045)^{1.75}}$

Comparatively, the expression of van Rijn (2007) relates the reference concentration for non-cohesive sediments to both the Shields parameter and the non-dimensional particle parameter

$D_{\star}=d\left[(s-1) g / \nu^{2}\right]^{1 / 3}$ :

$c_{\text {ref }}=0.015 \frac{d}{z_{\text {ref }}} \frac{\left(\theta / \theta_{c r}-1\right)^{1.5}}{D_{\star}^{0.3}}$

where $\theta_{c r}$ is the critical bed-shear stress according to Shields and the reference level is chosen as $z_{r e f}=20 d$ with a minimum value of $1 \mathrm{~cm}$.

\subsection{Numerical predictions}

Although it is dimensionally consistent with a concentration, the reference concentration really aims to parameterize the erosion flux. As such, comparisons between existing formulas and the numerical results should not use the numerical concentration per se but rather the ratio of the erosion flux over the settling velocity. The erosion flux itself is calculated from the net vertical flux and gravitational settling. All cases studied here present values for $U_{0} \omega /(s-1) g$ below 0.3 (table 1), and are thus expected to exhibit quasi-steadiness (Sleath, 1994), following which erosion and deposition should be in quasi-equilibrium. 
This is indeed observed for all cases, with erosion and deposition being about an order of magnitude greater than the net vertical flux and in quasi-equilibrium.

Numerical values for the reference concentration were calculated at a height of one centimetre above the undisturbed bed ( $20 d<1 \mathrm{~cm}$ for all our cases) for comparison with the van Rijn (2007) formula and at a height of twice the sediment diameter for comparison with the Zyserman and Fredsoe (1994) formula. Five examples (identical cases to those in figures 2 and 5) of the intrawave comparisons are presented in figures 9 and 10. There is a significant disagreement between the numerical results and the van Rijn (2007) formula, as neither the magnitude nor the phase of the reference concentration match. We attribute such discrepancy to the reference location employed being in the suspended region. It is always higher than twenty grain diameters from the undisturbed bed, and at such elevation, the vertical flux, the erosion and thus the reference concentration exhibit a phase lag with respect to the bed shear stress as observed in figure 9 .

Comparatively, there is a rather good agreement for the Zyserman and Fredsoe (1994) formula. Still, there is a small tendency for overprediction from the Zyserman and Fredsoe (1994) formula with respect to the numerical results for the higher bed shear stresses and there is a mismatch at flow reversals. The seemingly constant value for the numerical reference concentration is due to the combination of being in quasi-equilibrium between erosion and deposition, and the reference location being close to the top of the pickup layer. The quasi-equilibrium implies that the reference concentration is close to the actual concentration, which is somewhat constant at the top of the pickup layer (O'Donoghue and Wright, 2004). A wave-averaged reference concentration value can also be deduced from the wave-averaged erosion flux. Models then usually relate the reference concentration to some measure of the wave-current bed shear stress, usually the maximum value. Figure 11 presents the wave-averaged values for the numerical reference concentration and the comparison with Zyserman and Fredsoe (1994) and van Rijn (2007) formulas. While the Zyserman and Fredsoe (1994) formula gives values only modestly larger than the numerical model, there is a significant disagreement between the numerical results and the formula of van Rijn (2007). Such results for the reference concentration taken two diameters above the undisturbed bed are consistent with experimental results of O'Donoghue and Wright (2004) following which the concentration at $z=2 d$ is almost constant with time-averaged values ranging from about 0.2 to 0.25 for the medium and coarse sands.

\subsection{Comments on erosion parameterization}

Following from general dimensional analysis on sediment transport (e.g., Yalin, 1977), the dimensionless erosion rate should depend on the specific gravity of the sediment, the Shields parameter, the fall 
parameter $R_{p}=d \sqrt{(s-1) g d} / \nu$, and a dimensionless parameter involving the flow period $\Pi_{T}$.

$\frac{E}{\sqrt{(s-1) g d}}=f\left(s, \theta, R_{p}, \Pi_{T}\right)$

Since we are interested in sand transport in water, the specific gravity of the sediment is a constant. As mentioned previously we did not observe a significant dependence on the period in the range considered. The numerical results in figure 11 for different sediment diameters and flow conditions almost all collapse on a single curve, which seems to indicate that the relationship

$\frac{E}{W_{s}}=c_{r e f}(\theta)$

is a reasonable parameterization. This does not mean that the erosion rate is independent of the fall parameter but rather that it will follow the dependence of the fall velocity, i.e.

$E=W_{s}\left(R_{p}\right) c_{r e f}(\theta)$

It also appears from figure 11 that the reference concentration taken two diameters above the bed reaches a maximum with the bed shear stress that is smaller than the one incorporated in the Zyserman and Fredsoe (1994) formula. For the range of Shields parameters studied, this is not observed for the reference concentration one centimetre above the bed, for which there is a small linear increase of the reference concentration value with the bed shear stress.

In the case of the reference concentration very close to the bed $\left(z_{r e f}=2 d\right)$, a formula following the form of Amoudry et al. (2005)

$c_{r e f}(\theta)= \begin{cases}0 & \text { for } \quad \theta<\theta_{c} \\ c_{\max } \frac{\theta-\theta_{c}}{\theta_{s}-\theta_{c}} & \text { for } \quad \theta_{c}<\theta<\theta_{s} \\ c_{\max } & \text { for } \quad \theta_{s}<\theta\end{cases}$

where $c_{\max }=0.2, \theta_{s}=1.08$ and $\theta_{c}=0.15$ would give a reasonable approximation both of the Zyserman and Fredsoe (1994) formula for small to moderate Shields parameters and of the numerical results for high Shields parameters. The main discrepancy between equation 10 and Zyserman and Fredsoe (1994) occurs for small Shields parameter values, where the sheet flow numerical model can unfortunately not provide information. Using $c_{\max }=0.2$ as an upper-bound for the Zyserman and Fredsoe (1994) reference concentration would also lead to better agreement with the numerical data for the intrawave erosion. In the case of the reference concentration some distance from the bed $\left(z_{r e f}=1 \mathrm{~cm}\right)$, the linear dependence is best approximated by

$c_{\text {ref }}=6.1 \times 10^{-3} \theta_{\max }+7.9 \times 10^{-4}$

Naturally, this equation is only valid for the range of maximum Shields parameters considered in this paper (i.e. $1.2<\theta_{\max }<2$ ). In particular, equation 11 obviously fails to represent the correct processes 
both for very small stresses by predicting non zero erosion for zero bed shear stress and for very large stresses since it lacks an upper bound. Interestingly, such linear dependence of the reference concentration on the bed shear stress (in both cases) results in an erosion formulation similar to that for cohesive sediments $E=M\left[\tau_{b}-\tau_{c}\right]$ where both $M$ and the critical stress $\tau_{c}$ depend on the depth of erosion (e.g., Sanford and Maa, 2001).

Perhaps more importantly than providing information on erosion and deposition, the sheet flow numerical model calculates the instantaneous net vertical sediment flux (i.e. erosion minus deposition). In turn, we use these numerical results to attempt to directly model this quantity. Figure 12 shows ten examples for the intrawave vertical sediment flux two diameters above the undisturbed bed, including the five examples already shown in figures 2, 5,9 and 10. The solid line represents an attempt at modelling such flux as a function of the bed shear stress multiplied by its time derivative with a phase lag:

$E-D=C_{F}\left[\theta \frac{d \theta}{d t}\right]\left(\omega t+\phi_{e}\right)$

where $C_{F}=2.0 \times 10^{-4} \mathrm{~m}$. The physical reason for the term $\theta d \theta / d t$ is to consider that erosion can be due to accelerating flow independent of direction (i.e., for $\theta>0$ and $d \theta / d t>0$ or for $\theta<0$ and $d \theta / d t<0$ ). In general, there is a good agreement between equation 12 and the numerical data (the examples in figure 12 do include some of the worst cases). At flow reversals, the agreement is poor but this corresponds to times where the numerical model is the least accurate (Amoudry et al., 2008). For each case, equation 12 was tested by choosing the optimal phase lag for best agreement. The phase lag in equation 12 is then found to decrease with the value of the maximum bed shear stress (figure 13) following

$\phi_{e}=C_{\phi 1} \frac{\tau_{b \max }}{\rho}+C_{\phi 2}$

where $\phi_{e}$ is given in radians and $C_{\phi 1}=-58.6 \quad \mathrm{~s}^{2} / \mathrm{m}^{2}, C_{\phi 2}=0.86$.

\section{Conclusion}

We used a one-dimensional two-phase sheet flow model to study and discuss large-scale parameterizations of the bed shear stress, bed load transport rate and erosion rate. The model was validated in Amoudry et al. (2008) against laboratory data acquired under the sheet flow regime. The influence of the sediment diameter is investigated by varying the grain diameter within the range used previously for validation (i.e., $210 \mu \mathrm{m}$ to $460 \mu \mathrm{m})$. Different collinear wave and current flows are simulated by changing the current, the amplitude of the first two velocity harmonics, and the period.

The numerical bed shear stress results confirm several previous observations on the phase lead of the bed shear stress with respect to the free stream velocity. The formula of Madsen (1994) for the phase lead describes the present results well. Bed load transport rates are determined from the numerical results and 
are found to agree reasonably well with existing empirical formulations. Dependence with the sediment diameter is observed and investigated numerically. Bed load transport rates diminish with decreasing grain diameter, and an improved formula for the bed load transport rate is proposed based on the numerical results. The importance of the sediment bottom condition for intrawave modelling has already been mentioned (e.g., Hsu and Liu, 2004) and investigated (e.g., Amoudry et al., 2005). Here, the influence of the sediment diameter on the erosion rate corresponds to that of the settling velocity and thus confirms the applicability of the reference concentration. Furthermore, the numerical results are found to agree significantly better with the Zyserman and Fredsoe (1994) reference concentration formulation than with that of van Rijn (2007). We attribute the poor agreement in the latter case to an inappropriate reference location for sheet flows. Such results are consistent with the observations of Amoudry et al. (2005) on the bottom boundary condition for dilute intrawave sheet flow modelling. The present numerical results further suggest that the reference concentration taken two grain diameters above the undisturbed bed may be better represented by setting an upper limit at an approximate value of 0.2 , which is consistent with the experimental findings of O'Donoghue and Wright (2004).

These results can then be implemented in sediment transport models at a larger scale. The results concerning the bed load transport rate vindicate the implementation of existing formulations such as that of Soulsby and Damgaard (2005) in both intrawave models and wave-averaged models. They further suggest the use of a diameter-dependent multiplicating factor for the bed load transport rate, which would follow the relationship expressed in equation 4 . The present results on the reference concentration support the use of the Zyserman and Fredsoe (1994) formula with an upper limit around 0.2 for intrawave models aiming to resolve suspended sediment transport in the wave boundary layer under the sheet flow regime (e.g., Amoudry et al., 2005; Ruessink et al., 2009; Hassan and Ribberink, 2010). Alternatively, such models may implement equations 12 and 13 for the net vertical flux instead of the reference concentration approach. For wave-averaged coastal models, implementation of the present results (e.g., equations 10 and 11) may be less straightforward due to the sheet flow regime restriction and issues arising from the near-bed resolution. Typically, in such models the bottom grid may well be large enough to induce significant corrections emanating from the difference between near-bed grid elevations and the reference location. Such corrections are crucial and may be derived assuming a Rouse profile for the concentration. Finally, it has to be noted that the present numerical results could strongly benefit from further theoretical improvements. As mentioned in Amoudry et al. (2008), transport of sand under the sheet flow regime falls close to or past the limit for reasonable use of the collisional theory. This leads to discrepancies in the near-bed sediment fluxes and the inability of the model to reproduce fine sand $(d<200 \mu \mathrm{m})$ transport. We believe that both issues would benefit from theoretical description of the particle-particle interactions more complete than pure collisions. 


\section{Acknowledgments}

We wish to thank two anonymous reviewers for their comments, which greatly helped to improve the manuscript. L. O. Amoudry wishes to acknowledge the support of the Natural Environment Research Council (NERC), through core funding to the Proudman Oceanographic Laboratory. P. L.-F. Liu would like to acknowledge the support from National Science Foundation, New York Sea Grant Institute through research grants to Cornell University. He would also like to thank the Humboldt Foundation for the Research Award Fellowship.

\section{A. Two-phase sheet flow model description}

\section{A.1. Two-phase flow governing equations}

The model solves the following concentration-weighted averaged equations of motion for the sediment and fluid phase:

$\frac{\partial \rho_{f}(1-\bar{c})}{\partial t}+\frac{\partial \rho_{f}(1-\bar{c}) \tilde{u}_{i}^{f}}{\partial x_{i}}=0$

for the fluid phase continuity,

$\frac{\partial \rho_{s} \bar{c}}{\partial t}+\frac{\partial \rho_{s} \bar{c} \tilde{u}_{i}^{s}}{\partial x_{i}}=0$

for the sediment phase continuity,

$$
\begin{aligned}
\frac{\partial \rho_{f}(1-\bar{c}) \tilde{u}_{i}^{f}}{\partial t}= & -\frac{\partial \rho_{f}(1-\bar{c}) \tilde{u}_{i}^{f} \tilde{u}_{j}^{f}}{\partial x_{j}}+\rho_{f}(1-\bar{c}) g_{i} \\
& -(1-\bar{c}) \frac{\partial \bar{P}^{f}}{\partial x_{i}}+\frac{\partial \tau_{i j}^{f}}{\partial x_{j}} \\
& -\beta \bar{c}\left(\tilde{u}_{i}^{f}-\tilde{u}_{i}^{s}\right)+\beta \frac{\nu_{T}}{\sigma_{c}} \frac{\partial \bar{c}}{\partial x_{i}}
\end{aligned}
$$

for the fluid phase momentum conservation and

$$
\begin{aligned}
\frac{\partial \rho_{s} \bar{c} \tilde{u}_{i}^{s}}{\partial t}= & -\frac{\partial \rho_{s} \bar{c} \tilde{u}_{i}^{s} \tilde{u}_{j}^{s}}{\partial x_{j}}+\rho_{s} \bar{c} g_{i}-\bar{c} \frac{\partial \bar{P}^{f}}{\partial x_{i}}+\frac{\partial \tau_{i j}^{s}}{\partial x_{j}} \\
& +\beta \bar{c}\left(\tilde{u}_{i}^{f}-\tilde{u}_{i}^{s}\right)-\beta \frac{\nu_{T}}{\sigma_{c}} \frac{\partial \bar{c}}{\partial x_{i}}
\end{aligned}
$$

for the sediment phase momentum conservation. In these equations, $\bar{c}$ is the ensemble averaged sediment concentration, $\tilde{u}_{i}^{f}=\overline{(1-c) u_{i}^{f}} /(1-\bar{c})$ and $\tilde{u}_{i}^{s}=\overline{c u_{i}^{s}} / \bar{c}$ are respectively the $i^{t h}$ component of the concentration-weighted averaged fluid phase velocity and the concentration-weighted averaged sediment phase velocity. $\bar{P}^{f}$ is the ensemble-averaged fluid pressure, $\tau_{i j}^{f}$ and $\tau_{i j}^{s}$ are the fluid and sediment stresses. The last two terms in the momentum equations represent the interphase momentum transfer, where $\beta$ is a 
drag coefficient expressed as a function of the particle Reynolds number $R e_{r}=U_{r} d / \nu_{f}$ itself based on the relative velocity magnitude $U_{r}=\left|\vec{u}^{s}-\vec{u}^{f}\right|$ :

$\beta=\frac{\mu_{f}}{d^{2}}\left(18.0+0.3 \operatorname{Re}_{r}\right) \frac{1}{(1-\bar{c})^{n}}$

with $\mu_{f}$ the fluid viscosity. The concentration dependence expresses higher drag observed for a group of particles than for single particles and follows the experimental findings of Richardson and Zaki (1954) where $n$ is also a function of $R e_{r}$. The second of these terms, containing the concentration gradient, is often called turbulent suspension; and it represents the turbulent flux of sediment as modelled following the gradient diffusion hypothesis with $\nu_{T}$ the fluid turbulent eddy viscosity and $\sigma_{c}$ the Schmidt number. The two terms corresponding to the different mechanisms for sediment suspension, discussed in section 4 , are explicitly given in equation A.4 when applied to the vertical sediment velocity. The term $\beta\left(\nu_{T} / \sigma_{c}\right)(\partial \bar{c} / \partial z)$ corresponds to turbulent suspension, while the term $\left(\partial \tau_{z z}^{s} / \partial z\right)$ represents the inter-particle interactions. The ratios plotted in figure 4 are then each of these terms divided by their sum.

\section{A.2. Sediment stresses}

The closure scheme for the sediment stresses is based on different descriptions of the inter-particle interactions throughout the water column. In the sediment bed (below the solid line in figure 1), sediment particles are stationary and sediment stresses are not calculated. Above the bed the sediment stresses are calculated following a collisional granular flow theory (Jenkins, 1998) that is modified to account for the transition between the sediment's solid behaviour in the bed and the fluid-like behaviour above the bed. Far away from the bed, sediment concentration is dilute and the sediment stresses can be neglected. In the collisional region, the sediment stresses are calculated using the constitutive relations derived for collisional flows of identical, frictionless, nearly elastic spheres (Jenkins, 1998) and a balance equation for the particle fluctuating energy $k_{s}$ derived from the sediment-phase momentum equations. The balance equation for $k_{s}$ is

$$
\begin{aligned}
\frac{\partial \rho_{s} \bar{c} k_{s}}{\partial t}+\frac{\partial \rho_{s} \bar{c} k_{s} \tilde{u}_{j}^{s}}{\partial x_{j}}= & \tau_{i j}^{s} \frac{\partial \tilde{u}_{i}^{s}}{\partial x_{j}}-\frac{\partial \mathcal{Q}_{j}}{\partial x_{j}} \\
& -\gamma+2 \beta \bar{c}\left(\alpha k_{f}-k_{s}\right)
\end{aligned}
$$

where both the energy flux $\mathcal{Q}_{j}$ and the dissipation $\gamma$ are calculated using the collisional granular flow theory and expressed as functions of the sediment concentration, $k_{s}$ and other sediment properties (Jenkins, 1998). $\alpha$ is a parameter that measures the degree of correlation between the fluid velocity fluctuations and the sediment velocity fluctuations and is a function of several time scales involved (Hsu et al., 2004). The collisional sediment stress tensor is given by:

$$
\begin{aligned}
\tau_{i j}^{s c}= & \left(-p_{c}+\omega \frac{\partial \tilde{u}_{k}^{s}}{\partial x_{k}}\right) \delta_{i j} \\
& +\mu_{c}\left(\frac{\partial \tilde{u}_{i}^{s}}{\partial x_{j}}+\frac{\partial \tilde{u}_{j}^{s}}{\partial x_{i}}-\frac{2}{3} \frac{\partial \tilde{u}_{k}^{s}}{\partial x_{k}} \delta_{i j}\right)
\end{aligned}
$$


where the collisional pressure $p_{c}$, the bulk viscosity $\omega$, and the shear viscosity $\mu_{c}$ are also functions of the sediment concentration, $k_{s}$ and other sediment properties such as the grain diameter and the mass density (Jenkins, 1998).

Furthermore, the solid-like rigid structure of the bed is not broken at once to give rise to the fluid-like region but rather follows a transition where the particles first move while staying in contact and interacting frictionally with their neighbours. In this regime, which is taken to occur between the random close-packing value $c^{\star}=0.635$ (also the maximum possible concentration) and the random loose-packing value (lowest concentration so that grains remain in contact) $c_{\star}=0.57$, the effects of the frictional bonds need to be accounted for. In that concentration range, the collisional shear viscosity is greatly increased (Bocquet et al., 2001) and an extra normal stress component due to homogeneously packed identical spheres in Hertzian contact is also added to the total sediment stress (Hsu et al., 2004).

\section{A.3. Fluid turbulence closure}

The concentration-weighted averaged fluid Reynolds stresses are modelled using the turbulent eddy viscosity hypothesis and, following from the concentration-weighted average, we scale here the eddy viscosity using $k_{f}, \varepsilon_{f}$ and the concentration:

$\nu_{T}=C_{\mu} \frac{(1-\bar{c}) k_{f}^{2}}{\varepsilon_{f}}$.

Balance equations for both $k_{f}$ and $\varepsilon_{f}$ can be summarized as follows:

$$
\begin{aligned}
\frac{\partial K}{\partial t}+\frac{\partial K \tilde{u}_{j}^{f}}{\partial x_{j}}= & \mathcal{P}_{k}+\frac{\partial T_{j}^{k}}{\partial x_{j}}-E-D_{p}, \\
\frac{\partial E}{\partial t}+\frac{\partial E \tilde{u}_{i}^{f}}{\partial x_{i}}= & C_{\varepsilon 1} \frac{\varepsilon_{f}}{k_{f}} \mathcal{P}_{k}+\frac{\partial T_{j}^{\varepsilon}}{\partial x_{j}}-C_{\varepsilon 2} \frac{\varepsilon_{f}}{k_{f}} E \\
& -C_{\varepsilon 3} \frac{\varepsilon_{f}}{k_{f}} D_{p},
\end{aligned}
$$

where $K=\rho_{f}(1-\bar{c}) k_{f}, E=\rho_{f}(1-\bar{c}) \varepsilon_{f}$. In the balance equations, $\mathcal{P}_{k}$ is the shear production of kinetic energy, $T^{k}$ and $T^{\varepsilon}$ are transport terms both modelled following a gradient diffusion assumption:

$T_{j}^{k}=\left(\nu+\frac{\nu_{T}}{\sigma_{k}}\right) \frac{\partial K}{\partial x_{j}} \quad$ and $\quad T_{j}^{\varepsilon}=\left(\nu+\frac{\nu_{T}}{\sigma_{\varepsilon}}\right) \frac{\partial E}{\partial x_{j}}$

The last term in equations A.9 and A.10, $D_{p}$, is due to the phase interaction drag terms in the fluid momentum equation. It can be either an additional dissipative term $\left(D_{p}>0\right)$ for the turbulent energy or an extra production term $\left(D_{p}<0\right)$ and is expressed as

$D_{p}=2 \beta(1-\alpha) \bar{c} k_{f}-\beta \frac{\nu_{T}}{\sigma_{c}} \frac{\partial \bar{c}}{\partial z}\left(\tilde{w}_{f}-\tilde{w}_{s}\right)$

Complete closure of the turbulence model requires the specification of $\sigma_{c}, C_{\mu}, C_{\varepsilon 1}, C_{\varepsilon 2}, C_{\varepsilon 3}, \sigma_{k}$ and $\sigma_{\varepsilon}$. Common values for these coefficients are $\sigma_{c}=1.0, C_{\mu}=0.09, C_{\varepsilon 1}=1.44, C_{\varepsilon 2}=1.92, C_{\varepsilon 3}=1.2, \sigma_{k}=1.0$ 
and $\sigma_{\varepsilon}=1.3$, which are the same as the clear fluid values and a $C_{\varepsilon 3}$ value chosen based on sediment-laden jets results (Elghobashi and Abou-Arab, 1983). Here, $C_{\varepsilon 2}$ is modified following Amoudry et al. (2008)

$C_{\varepsilon 2}=C_{\varepsilon 20}\left[1+\max \left(c_{1} \ln \left(c_{2} \frac{T_{F}}{T_{p}}\right), 0\right) \frac{\bar{c}}{c^{\star}}\right]$,

where $C_{\varepsilon 20}=1.92, c_{1}=2.4$ and $c_{2}=2$.

\section{References}

Amoudry, L., Hsu, T.-J., Liu, P. L.-F., 2005. Schmidt number and near-bed boundary condition effects on a two-phase dilute sediment transport model. J. Geophys. Res. 110 (C09003).

Amoudry, L., Hsu, T.-J., Liu, P. L.-F., 2008. Two-phase model for sand transport in sheet flow regime. J. Geophys. Res. $113(\mathrm{C} 03011)$.

Amoudry, L. O., 2008. Two-phase modeling of granular sediment for sheet flows and scour. Ph.D. thesis, Cornell University.

Amoudry, L. O., Liu, P. L.-F., 2009. Two-dimensional, two-phase granular sediment transport model with applications to scouring downstream of an apron. Coastal Eng. 56 (7), 693-702.

Asano, T., 1995. Sediment transport under sheet-flow conditions. J. Waterw. Port Coastal Ocean Eng. 121 (5), $239-246$.

Bagnold, R. A., 1966. An approach to the sediment transport problem from general physics. Geological Survey Professional Paper 422-I.

Bocquet, L., Losert, W., Schalk, D., Lubensky, T. C., Gollub, J. P., 2001. Granular shear flow dynamics and forces: experiment and continuum theory. Phys. Rev. E 65.

Dohmen-Janssen, C. M., 1999. Grain size influence on sediment transport in oscillatory sheet flow, phase lags and mobile-bed effects. Ph.D. thesis, Delft Univiversity of Technology.

Dong, P., Zhang, K., 2002. Intense near-bed sediment motions in waves and currents. Coastal Eng. 45, $75-87$.

Drake, T. G., Calantoni, J., 2001. Discrete particle model for sheet flow sediment transport in the nearshore. J. Geophys. Res. 106 (C9), 19,859-19,868.

Dudley, R. D., 2007. A boroscopic quantitative technique for sheet flow measurements. Master's thesis, Cornell University.

Elghobashi, S. E., Abou-Arab, T. W., 1983. A two-equation turbulence model for two-phase flows. Phys. Fluids 26 (4), 931-938.

Fernandez Luque, R., van Beek, R., 1976. Erosion and transport of bed-load sediment. J. Hydrau. Res. 14 (2), $127-144$.

Garcia, M., Parker, G., 1991. Entrainment of bed sediment into suspension. J. Hydraul. Eng. 117 (4), 414-435.

Gonzalez-Rodriquez, D., Madsen, O. S., 2007. Seabed stress and bedload transport due to asymmetric and skewed waves. Coastal Eng. 54, 914-929.

Grant, W. D., Madsen, O. S., 1979. Combined wave and current interaction with a rough bottom. J. Geophys. Res. 84 (C4), $1797-1808$.

Grasmeijer, B. T., Davies, A. G., Guizien, K., van der Werf, J. J., van Rijn, L. C., Walther, R., Sutherland, J., Biegowski, J., 2005. Intercomparison results of sand transport models based on blind benchmarking test cases. In: van Rijn, L. C., Soulsby, R. L., Hoekstra, P., Davies, A. G. (Eds.), SANDPIT: Sand Transport and Morphology of Offshore Sand Mining Pits. Aqua Publications, pp. AM1-AM10.

Guizien, K., Dohmen-Janssen, C. M., Vittori, G., 2003. 1DV bottom boundary layer modeling under combined wave and current: Turbulent separation and phase lag effects. J. Geophys. Res. 108 (3016).

Harris, C. K., Wiberg, P. L., 2001. A two-dimensional, time-dependent model of suspended sediment transport and bed reworking for continental shelves. Computers and Geosciences 27, 675-690. 
Hassan, W. N. M., Ribberink, J. S., 2010. Modelling of sand transport under wave-generated sheet flows with a RANS diffusion model. Coastal Eng. 57, 19-29.

Hsu, T.-J., Elgar, S., Guza, R. T., 2006. Wave-induced sediment transport and onshore sandbar migration. Coastal Eng. 53, $817-824$

Hsu, T.-J., Hanes, D. M., 2004. Effects of wave shape on sheet flow sediment transport. J. Geophys. Res. 109 (C05025).

Hsu, T.-J., Jenkins, J. T., Liu, P. L.-F., 2004. On two-phase sediment transport: sheet flow of massive particles. Proc. Roy. Soc. London, Ser. A 460 .

Hsu, T.-J., Liu, P. L.-F., 2004. Toward modeling turbulent suspension of sand in the nearshore. J. Geophys. Res. 109 (C06018).

Jenkins, J. T., 1998. Kinetic theory for nearly elastic spheres. In: H.J. Herrmann, J.P. Hovi, S. Luding (Ed.), Physics of dry granular media. Springer, Dordrecht, Netherland, pp. 353-369.

Jenkins, J. T., Hanes, D. M., 1998. Collisional sheet flows of sediment driven by a turbulent fluid. J. Fluid Mech. 370, 29-52.

Jensen, B. L., Sumer, B. M., Fredsøe, J., 1989. Turbulent oscillatory boundary layers at high reynolds numbers. J. Fluid Mech. 206, 265-297.

Justesen, P., 1991. A note on turbulence calculations in the wave boundary layer. J. Hydrau. Res. 29 (5), 699-711.

Kleinhans, M. G., Grasmeijer, B. T., 2006. Bed load transport on the shoreface by currents and waves. Coastal Eng. 53, 983-996.

Lesser, G. R., Roelvink, J. A., van Kester, J., Stelling, G. S., 2004. Development and validation of a three-dimensional morphological model. Coastal Eng. 51 (8-9), 883-915.

Li, M., Pan, S., O'Connor, B. A., 2008. A two-phase numerical model for sediment transport prediction under oscillatory sheet flows. Coastal Eng. 55, 1159-1173.

Madsen, O. S., 1994. Spectral wave-current bottom boundary layer flows. In: Coastal Engineering. Proceedings, 24th International Conference Coastal Engineering. pp. 384-398.

Malarkey, J., Davies, A. G., 2002. Discrete vortex modelling of oscillatory flow over ripples. Applied Ocean Research 24, $127-145$.

McLean, S. R., Ribberink, J. S., Dohmen-Janssen, C. M., Hassan, W. N., 2001. Sand transport in oscillatory sheet flow with mean current. J. Waterw. Port Coastal Ocean Eng. 127 (3), 141-151.

Meyer-Peter, E., Müller, R., 1948. Formulas for bed-load transport. In: Proc. 2nd IAHR Congress, Stockholm. pp. 39-64.

Nielsen, P., Callaghan, D. P., 2003. Shear stress and sediment transport calculations for sheet flow under waves. Coastal Eng. $47,347-354$.

O’Donoghue, T., Wright, S., 2004. Concentrations in oscillatory sheet flow for well sorted and graded sands. Coastal Eng. 50, $117-138$.

Ribberink, J. S., 1998. Bed-load transport for steady flows and unsteady oscillatory flows. Coastal Eng. 34, 59-82.

Richardson, J. F., Zaki, W. N., 1954. Sedimentation and fluidization. Trans. Instn. Chem. Egnrs. 32, 35-53.

Ruessink, B. G., van der Berg, T. J. J., van Rijn, L. C., 2009. Modeling sediment transport beneath skewed-asymmetric waves above a plane bed. J. Geophys. Res. 114 (C11021).

Sanford, L. P., Maa, J. P.-Y., 2001. A unified erosion formulation for fine sediments. Marine Geology 179, 9-23.

Sleath, J. F. A., 1994. Sediment transport in oscillatory flow. In: Belorgey, M., Rajaona, R., Sleath, J. (Eds.), Sediment transport mechanisms in coastal environments and rivers. World Scientific.

Smith, J. D., McLean, S. R., 1977. Spatially averaged flow over a wavy surface. J. Geophys. Res. 82 (12), $1735-1746$.

Soulsby, R. L., Damgaard, J. S., 2005. Bedload sediment transport in coastal waters. Coastal Eng. 52 (8), 673-689.

Sumer, B. M., Kozakiewicz, A., Fredsoe, J., Deigaard, R., 1996. Velocity and concentration profiles in sheet-flow layer of movable bed. J. Hydraul. Eng. 122 (10), 549-558. 
van Rijn, L. C., 1984. Sediment transport, part II: Suspended load transport. J. Hydraul. Eng. 110 (11), 1613-1641.

van Rijn, L. C., 2007. Unified view of sediment transport by currents and waves. II: Suspended transport. J. Hydraul. Eng.

$133(6), 668-688$.

Vittori, G., 2003. Sediment suspension due to waves. J. Geophys. Res. 108 (3173).

Walstra, D. J. R., Chesher, T., Davies, A. G., Ribberink, J., Sergent, P., Silva, P., Vittori, G., Walther, R., van Rijn, L. C., 2005. Intercomparison of the state of the morphological models. In: van Rijn, L. C., Soulsby, R. L., Hoekstra, P., Davies, A. G. (Eds.), SANDPIT: Sand Transport and Morphology of Offshore Sand Mining Pits. Aqua Publications, pp. AY1-AY23.

Warner, J. C., Sherwood, C. R., Signell, R. P., Harris, C. K., Arango, H. G., 2008. Development of a three-dimensional, regional, coupled wave, current, and sediment transport model. Computers and Geosciences 34, 1284-1306.

Wiberg, P. L., Rubin, D. M., 1989. Bed roughness produced by saltating sediment. J. Geophys. Res. 94 (C4), $5011-5016$.

Wilson, K. C., 1966. Bed-load transport at high shear stress. J. of the Hydraulics Division 92 (HY6), $49-59$.

Yalin, M. S., 1977. Mechanics of sediment transport, 2nd Edition. Pergamon Press.

Zedler, E. A., Street, R. L., 2001. Large-eddy simulation of sediment transport: currents over ripples. J. Hydraul. Eng. 127 (6), 444-452.

Zedler, E. A., Street, R. L., 2006. Sediment transport over ripples in oscillatory flow. J. Hydraul. Eng. 132 (2), $180-193$.

Zhao, Z., Fernando, H. J. S., 2007. Numerical simulation of scour around pipelines using an euler-euler coupled two-phase model. Environmental Fluid Mech. 7, 121-142.

Zyserman, J. A., Fredsoe, J., 1994. Data analysis of bed concentration of suspended sediment. J. Hydraul. Eng. 120 (9), $1021-1042$. 
Table 1: Characteristics of cases numerically simulated.

\begin{tabular}{|c|c|c|c|c|c|c|c|}
\hline Case number & $d(\mu \mathrm{m})$ & $\mathrm{T}(\mathrm{s})$ & $U_{0 c}(\mathrm{~m} / \mathrm{s})$ & $U_{01}(\mathrm{~m} / \mathrm{s})$ & $U_{02}(\mathrm{~m} / \mathrm{s})$ & $\theta_{\max }$ & $\frac{U_{01} \omega}{(s-1) g}$ \\
\hline 1 & 210 & 7.2 & 0.00 & 1.40 & 0.24 & 2.14 & 0.08 \\
\hline 2 & 210 & 7.2 & 0.00 & 1.71 & 0.00 & 2.17 & 0.09 \\
\hline 3 & 210 & 7.2 & 0.12 & 1.20 & 0.00 & 1.66 & 0.06 \\
\hline 4 & 210 & 7.2 & 0.14 & 1.30 & 0.00 & 1.76 & 0.07 \\
\hline 5 & 210 & 7.2 & 0.17 & 1.41 & 0.00 & 1.87 & 0.08 \\
\hline 6 & 210 & 7.2 & 0.28 & 1.48 & 0.00 & 1.95 & 0.08 \\
\hline 7 & 210 & 7.2 & 0.33 & 1.41 & 0.00 & 2.01 & 0.08 \\
\hline 8 & 230 & 7.2 & 0.01 & 1.20 & 0.00 & 1.52 & 0.06 \\
\hline 9 & 230 & 7.2 & 0.11 & 1.20 & 0.00 & 1.57 & 0.06 \\
\hline 10 & 230 & 7.2 & 0.13 & 1.30 & 0.00 & 1.75 & 0.07 \\
\hline 11 & 230 & 7.2 & 0.17 & 1.41 & 0.00 & 1.80 & 0.08 \\
\hline 12 & 230 & 7.2 & 0.26 & 1.48 & 0.00 & 1.98 & 0.08 \\
\hline 13 & 230 & 7.2 & 0.32 & 1.41 & 0.00 & 1.96 & 0.08 \\
\hline 14 & 250 & 7.2 & 0.01 & 1.20 & 0.00 & 1.53 & 0.06 \\
\hline 15 & 250 & 7.2 & 0.10 & 1.20 & 0.00 & 1.57 & 0.06 \\
\hline 16 & 250 & 7.2 & 0.13 & 1.31 & 0.00 & 1.71 & 0.07 \\
\hline 17 & 250 & 7.2 & 0.15 & 1.41 & 0.00 & 1.75 & 0.08 \\
\hline 18 & 250 & 7.2 & 0.33 & 1.47 & 0.00 & 1.95 & 0.08 \\
\hline 19 & 250 & 7.2 & 0.30 & 1.41 & 0.00 & 1.87 & 0.08 \\
\hline 20 & 270 & 7.5 & 0.00 & 1.20 & 0.31 & 1.79 & 0.06 \\
\hline 21 & 270 & 7.2 & 0.01 & 1.21 & 0.00 & 1.48 & 0.07 \\
\hline 22 & 270 & 7.2 & 0.10 & 1.21 & 0.00 & 1.52 & 0.07 \\
\hline 23 & 270 & 7.2 & 0.12 & 1.31 & 0.00 & 1.63 & 0.07 \\
\hline 24 & 270 & 7.2 & 0.16 & 1.41 & 0.00 & 1.72 & 0.08 \\
\hline 25 & 270 & 7.2 & 0.33 & 1.48 & 0.00 & 1.88 & 0.08 \\
\hline 26 & 270 & 7.2 & 0.31 & 1.41 & 0.00 & 1.83 & 0.08 \\
\hline 27 & 300 & 7.2 & 0.00 & 1.21 & 0.00 & 1.47 & 0.07 \\
\hline 28 & 300 & 7.2 & 0.10 & 1.21 & 0.00 & 1.50 & 0.07 \\
\hline 29 & 300 & 7.2 & 0.13 & 1.31 & 0.00 & 1.61 & 0.07 \\
\hline 30 & 300 & 7.2 & 0.17 & 1.41 & 0.00 & 1.68 & 0.08 \\
\hline
\end{tabular}

(continued on next page) 
Table 1: Characteristics of cases numerically simulated. (continued)

\begin{tabular}{|c|c|c|c|c|c|c|c|}
\hline Case number & $d(\mu \mathrm{m})$ & $\mathrm{T}(\mathrm{s})$ & $U_{0 c}(\mathrm{~m} / \mathrm{s})$ & $U_{01}(\mathrm{~m} / \mathrm{s})$ & $U_{02}(\mathrm{~m} / \mathrm{s})$ & $\theta_{\max }$ & $\frac{U_{01} \omega}{(s-1) g}$ \\
\hline 31 & 300 & 7.2 & 0.33 & 1.48 & 0.00 & 1.81 & 0.08 \\
\hline 32 & 300 & 7.2 & 0.31 & 1.42 & 0.00 & 1.74 & 0.08 \\
\hline 33 & 320 & 7.2 & 0.00 & 1.11 & 0.13 & 1.47 & 0.06 \\
\hline 34 & 320 & 7.2 & 0.00 & 1.21 & 0.15 & 1.57 & 0.07 \\
\hline 35 & 320 & 7.2 & 0.00 & 1.31 & 0.19 & 1.66 & 0.07 \\
\hline 36 & 320 & 7.2 & 0.00 & 1.42 & 0.22 & 1.68 & 0.08 \\
\hline 37 & 320 & 7.2 & 0.00 & 1.55 & 0.48 & 1.84 & 0.08 \\
\hline 38 & 320 & 7.2 & 0.00 & 1.72 & 0.00 & 1.80 & 0.09 \\
\hline 39 & 320 & 7.2 & -0.03 & 1.01 & 0.00 & 1.25 & 0.05 \\
\hline 40 & 320 & 7.2 & -0.02 & 1.11 & 0.00 & 1.31 & 0.06 \\
\hline 41 & 320 & 7.2 & 0.04 & 1.52 & 0.41 & 1.83 & 0.08 \\
\hline 42 & 320 & 7.2 & 0.05 & 1.11 & 0.00 & 1.33 & 0.06 \\
\hline 43 & 320 & 7.2 & 0.06 & 1.21 & 0.00 & 1.47 & 0.07 \\
\hline 44 & 320 & 7.2 & 0.10 & 1.31 & 0.00 & 1.59 & 0.07 \\
\hline 45 & 320 & 7.2 & 0.14 & 1.42 & 0.00 & 1.66 & 0.08 \\
\hline 46 & 320 & 7.2 & 0.13 & 1.52 & 0.31 & 1.82 & 0.08 \\
\hline 47 & 320 & 7.2 & 0.33 & 1.48 & 0.00 & 1.76 & 0.08 \\
\hline 48 & 320 & 5.4 & 0.36 & 1.46 & 0.00 & 1.82 & 0.11 \\
\hline 49 & 320 & 9.0 & 0.32 & 1.50 & 0.00 & 1.69 & 0.06 \\
\hline 50 & 320 & 7.2 & 0.29 & 1.52 & 0.00 & 1.70 & 0.08 \\
\hline 51 & 320 & 7.2 & 0.34 & 1.53 & 0.00 & 1.72 & 0.08 \\
\hline 52 & 320 & 7.2 & 0.54 & 1.52 & 0.00 & 1.77 & 0.08 \\
\hline 53 & 320 & 7.2 & 0.64 & 1.53 & 0.00 & 1.73 & 0.08 \\
\hline 54 & 350 & 7.2 & 0.00 & 1.22 & 0.00 & 1.44 & 0.07 \\
\hline 55 & 350 & 7.2 & 0.09 & 1.22 & 0.00 & 1.47 & 0.07 \\
\hline 56 & 350 & 7.2 & 0.13 & 1.32 & 0.00 & 1.59 & 0.07 \\
\hline 57 & 350 & 7.2 & 0.17 & 1.42 & 0.00 & 1.65 & 0.08 \\
\hline 58 & 350 & 7.2 & 0.33 & 1.48 & 0.00 & 1.71 & 0.08 \\
\hline 59 & 350 & 7.2 & 0.31 & 1.42 & 0.00 & 1.72 & 0.08 \\
\hline
\end{tabular}

(continued on next page) 
Table 1: Characteristics of cases numerically simulated. (continued)

\begin{tabular}{|c|c|c|c|c|c|c|c|}
\hline Case number & $d(\mu \mathrm{m})$ & $\mathrm{T}(\mathrm{s})$ & $U_{0 c}(\mathrm{~m} / \mathrm{s})$ & $U_{01}(\mathrm{~m} / \mathrm{s})$ & $U_{02}(\mathrm{~m} / \mathrm{s})$ & $\theta_{\max }$ & $\frac{U_{01} \omega}{(s-1) g}$ \\
\hline 60 & 370 & 7.2 & 0.00 & 1.22 & 0.00 & 1.43 & 0.07 \\
\hline 61 & 370 & 7.2 & 0.08 & 1.22 & 0.00 & 1.46 & 0.07 \\
\hline 62 & 370 & 7.2 & 0.12 & 1.32 & 0.00 & 1.60 & 0.07 \\
\hline 63 & 370 & 7.2 & 0.16 & 1.42 & 0.00 & 1.62 & 0.08 \\
\hline 64 & 370 & 7.2 & 0.32 & 1.49 & 0.00 & 1.71 & 0.08 \\
\hline 65 & 370 & 7.2 & 0.30 & 1.42 & 0.00 & 1.68 & 0.08 \\
\hline 66 & 400 & 7.2 & 0.00 & 1.23 & 0.00 & 1.42 & 0.07 \\
\hline 67 & 400 & 7.2 & 0.08 & 1.23 & 0.00 & 1.46 & 0.07 \\
\hline 68 & 400 & 7.2 & 0.12 & 1.33 & 0.00 & 1.58 & 0.07 \\
\hline 69 & 400 & 7.2 & 0.16 & 1.43 & 0.00 & 1.62 & 0.08 \\
\hline 70 & 400 & 7.2 & 0.31 & 1.49 & 0.00 & 1.67 & 0.08 \\
\hline 71 & 400 & 7.2 & 0.30 & 1.43 & 0.00 & 1.67 & 0.08 \\
\hline 72 & 430 & 7.2 & 0.00 & 1.23 & 0.00 & 1.42 & 0.07 \\
\hline 73 & 430 & 7.2 & 0.08 & 1.23 & 0.00 & 1.47 & 0.07 \\
\hline 74 & 430 & 7.2 & 0.12 & 1.33 & 0.00 & 1.56 & 0.07 \\
\hline 75 & 430 & 7.2 & 0.30 & 1.49 & 0.00 & 1.65 & 0.08 \\
\hline 76 & 460 & 7.5 & 0.00 & 1.22 & 0.37 & 1.56 & 0.06 \\
\hline 77 & 460 & 7.2 & 0.00 & 1.24 & 0.00 & 1.44 & 0.07 \\
\hline 78 & 460 & 7.2 & 0.07 & 1.24 & 0.00 & 1.48 & 0.07 \\
\hline 79 & 460 & 7.2 & 0.11 & 1.33 & 0.00 & 1.53 & 0.07 \\
\hline
\end{tabular}


Table 2: Coefficients in bed load predictors

\begin{tabular}{lccc}
\hline Predictor & $m$ & $n$ & $p$ \\
\hline Meyer-Peter and Müller (1948) & 8 & 0 & 1.5 \\
\hline Wilson (1966) & 12 & 1.5 & 0 \\
\hline Fernandez Luque and van Beek (1976) & 5.7 & 0 & 1.5 \\
\hline Ribberink (1998) & 11 & 0 & 1.65 \\
\hline Soulsby and Damgaard (2005) & 12 & 0.5 & 1 \\
\hline Kleinhans and Grasmeijer (2006) & 1 & 0 & 1.5 \\
\hline
\end{tabular}

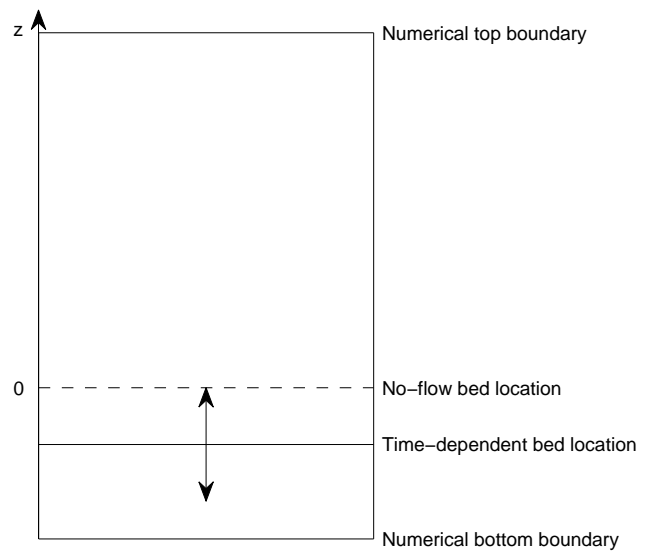

Figure 1: Sketch of the numerical domain for the sheet flow model. 


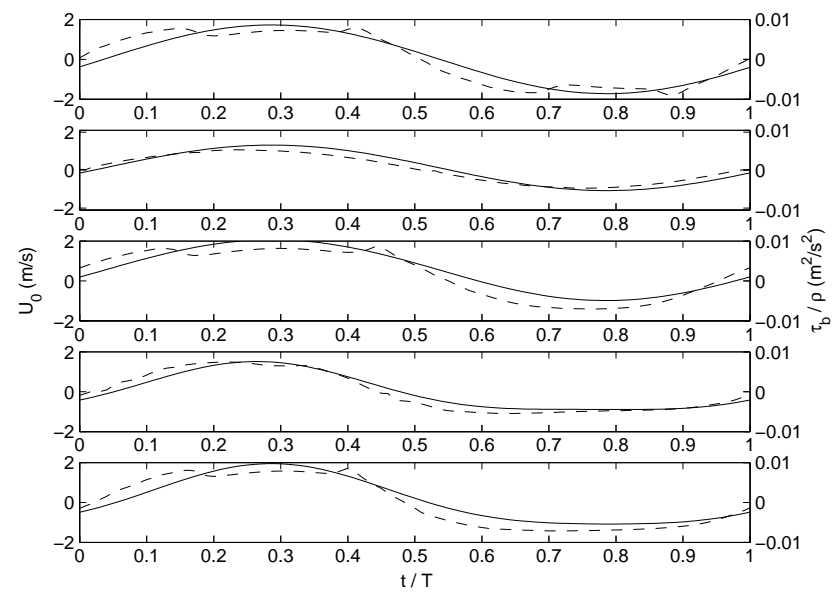

Figure 2: Free-stream velocity (solid lines) and non-dimensional bed shear stress (dashed lines) for five cases from table 1. From top to bottom: case 38, pure oscillatory flow; cases 3 and 52, sinusoidal wave plus current; case 20, 2nd-order Stokes wave; and case 46, 2nd-order Stokes wave and current.

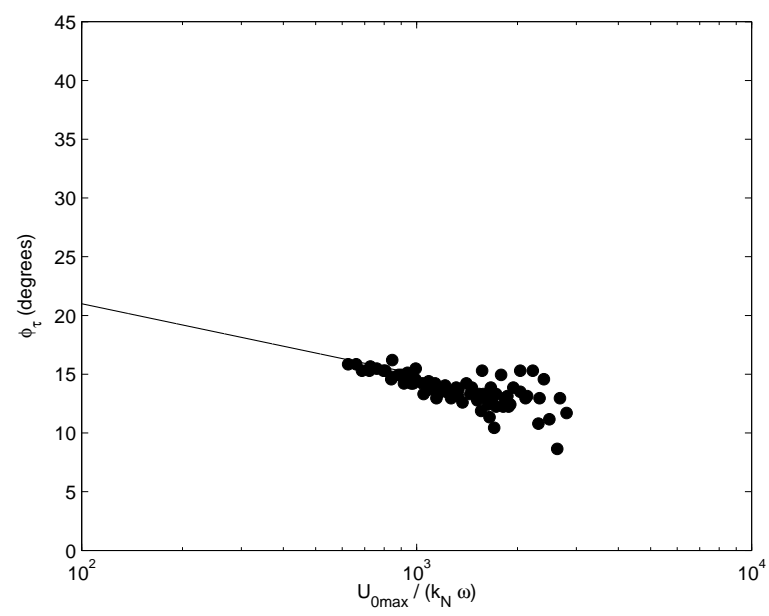

Figure 3: Phase lead of the bed shear stress with respect to the free stream velocity for all numerically simulated cases (circles) and following the expression of Madsen (1994) (solid line). 


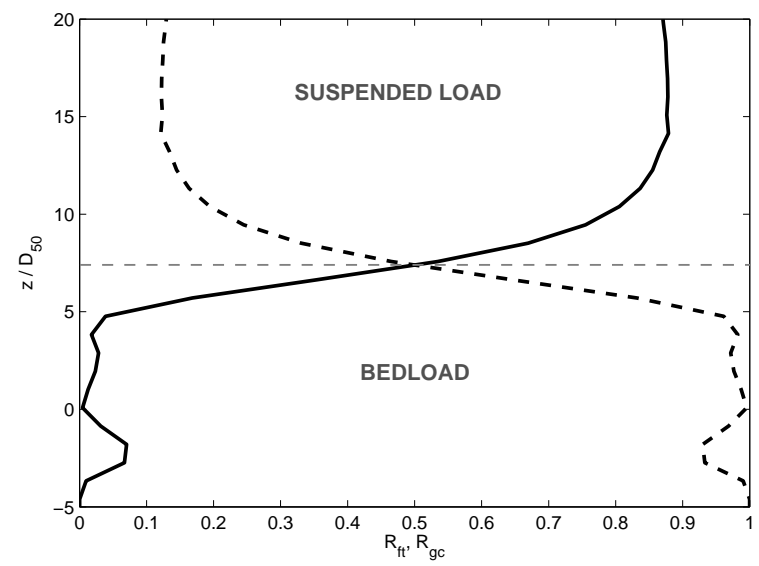

Figure 4: Example of ratio of total sediment suspension due to turbulent suspension $R_{f t}$ in the solid line and to the sediment stress gradient $R_{g c}$ in the dashed line (see appendix for more details on the ratios). The transition between bed load and suspended load occurs at the intersection of the two curves.

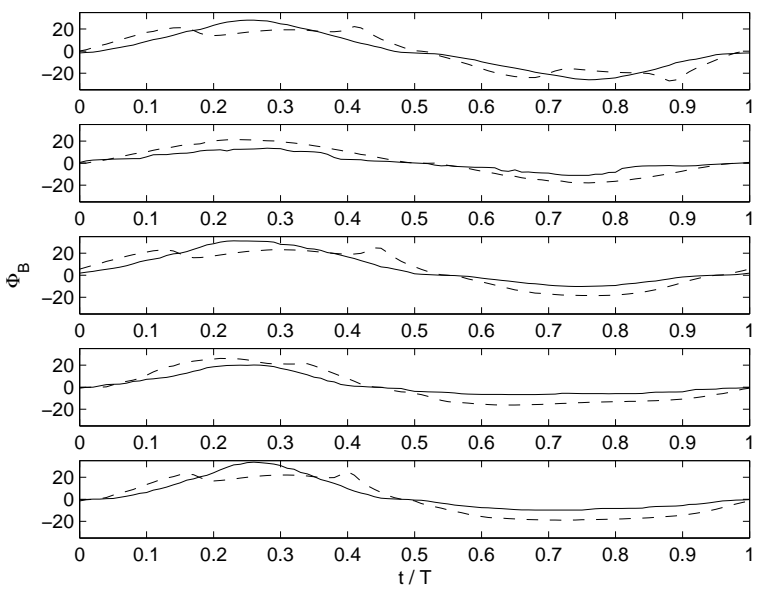

Figure 5: Bed load transport rate comparison between the numerical sheet flow model results (solid line) and the quasi-steady empirical formula of Soulsby and Damgaard (2005) (dashed line) for the five examples of figure 2. 


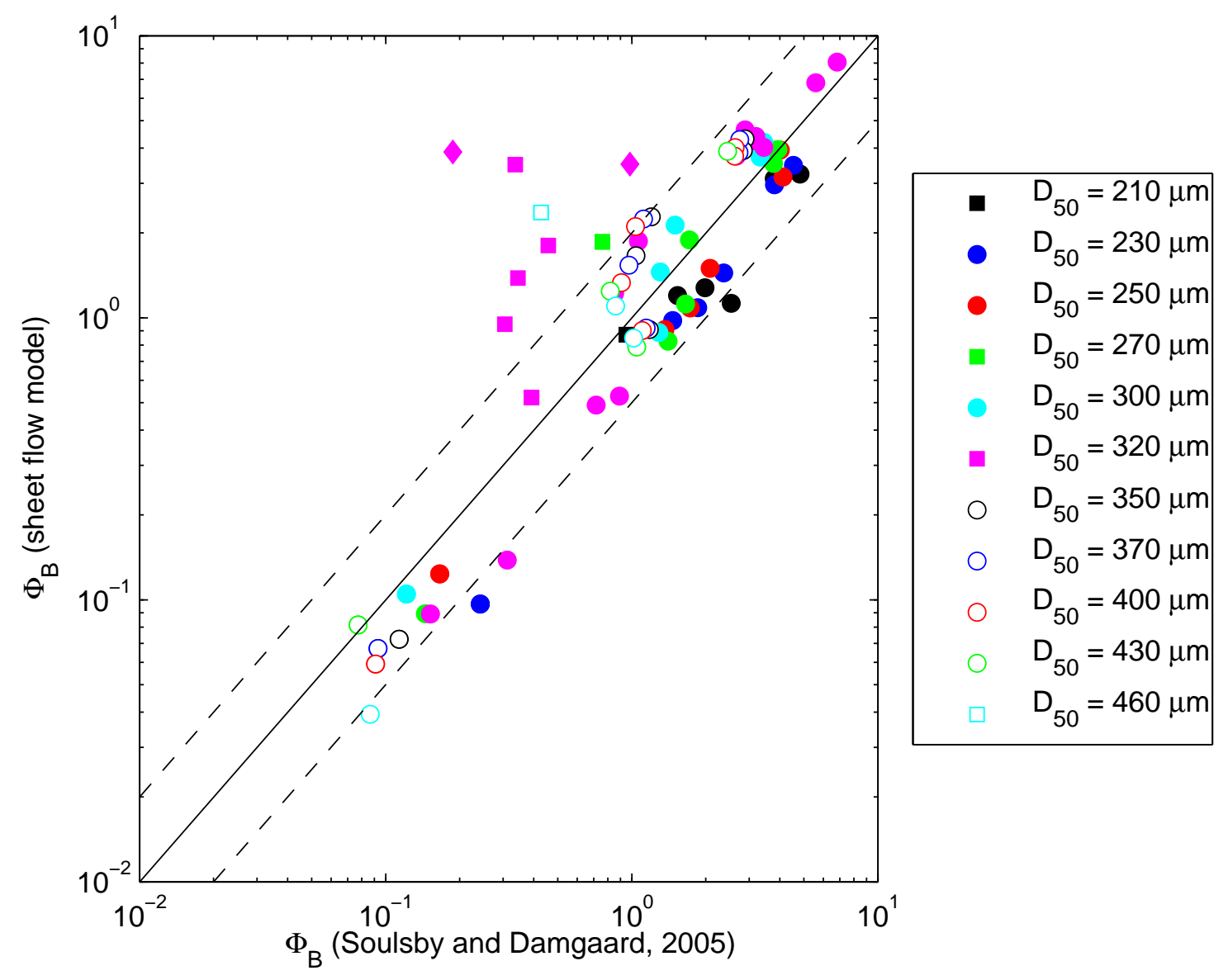

Figure 6: Net bed load transport rate comparison between numerical results using Amoudry et al. (2008) and Soulsby and Damgaard (2005)'s formula. Circles: current and sinusoidal wave. Squares: 2nd-order Stokes waves. Diamonds: 2nd-order Stokes waves with superposed current. Dashed lines: factor two error.

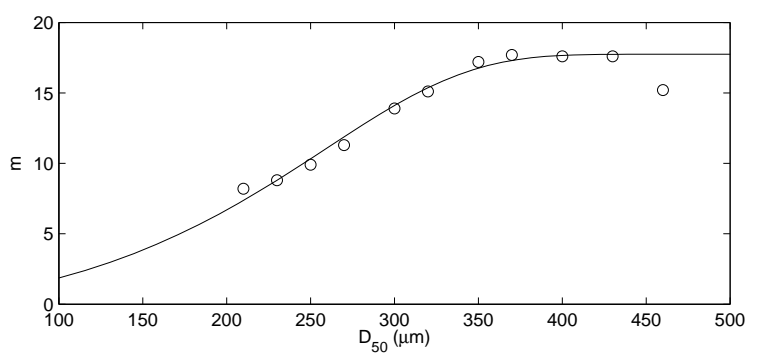

Figure 7: Bed load formula proportionality factor $m$ as function of sediment diameter. The solid line represents equation 4. 


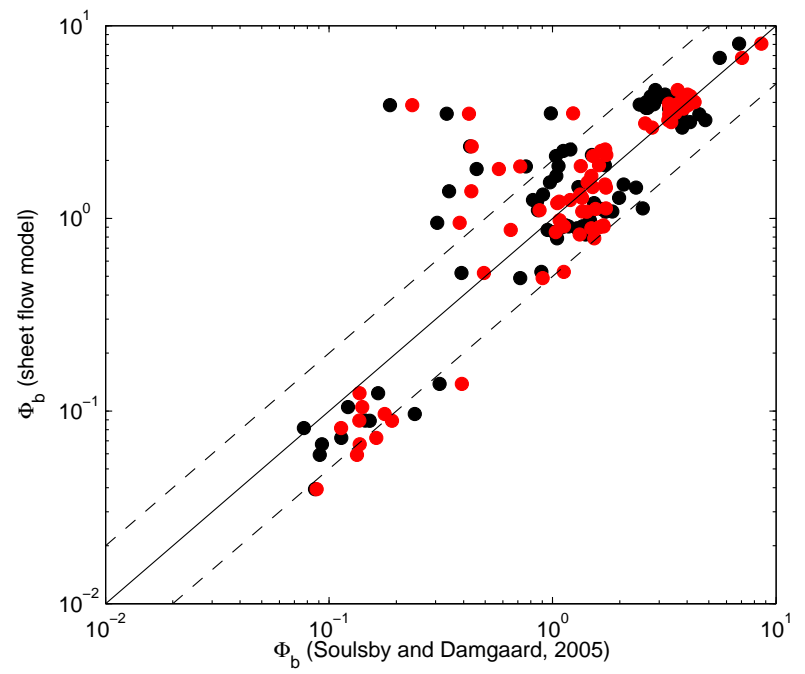

Figure 8: Net bed load transport rate comparison between the sheet flow model numerical results and Soulsby and Damgaard (2005)'s formula without equation 4 (black) and with equation 4 (red).

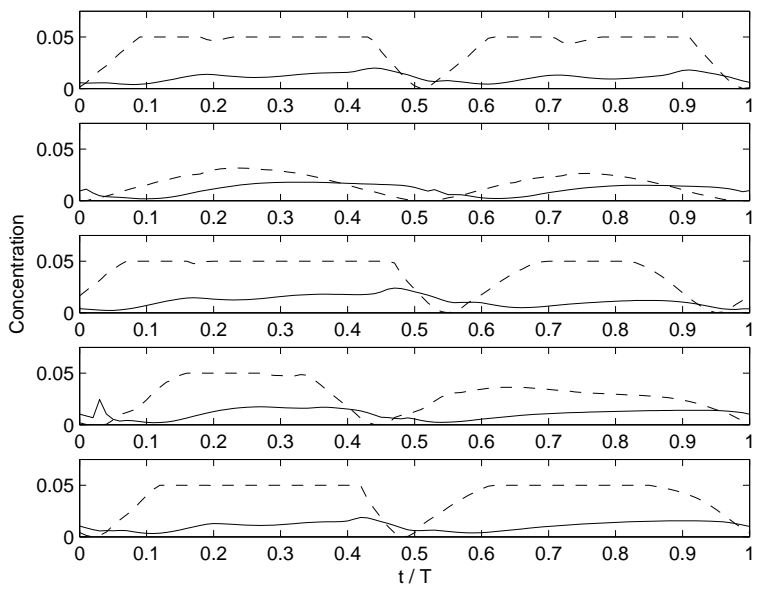

Figure 9: Examples of intra-wave reference concentration for the numerical results (solid line) and for van Rijn (2007) formula (dashed lines) for the five examples of figure 2 . 


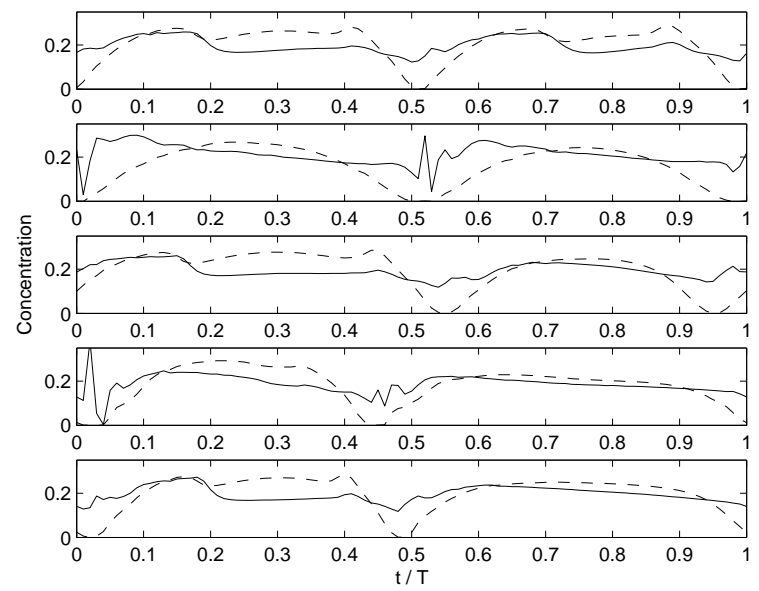

Figure 10: Examples of intra-wave reference concentration for the numerical results (solid line) and for Zyserman and Fredsoe (1994) formula (dashed lines) for the five examples of figure 2.
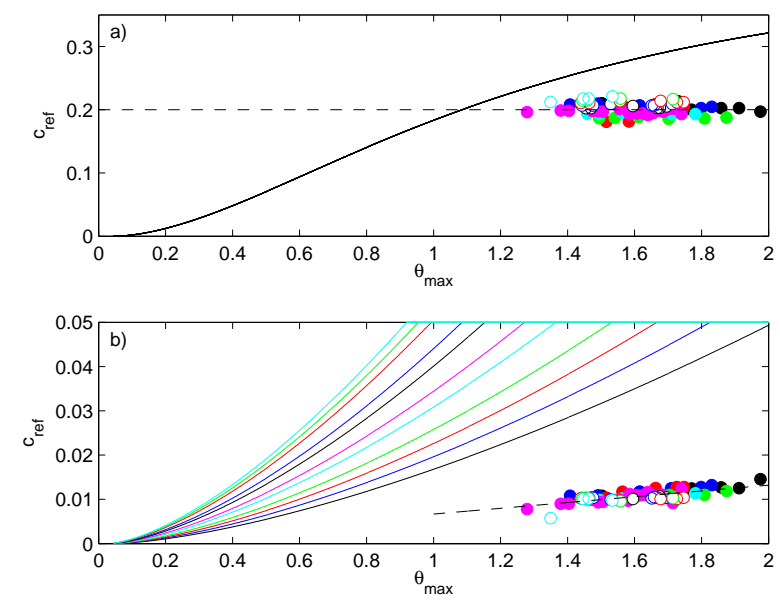

Figure 11: Wave-averaged reference concentration. a) Comparison between the numerical results (symbols with the same colour legend as in figure 6) and Zyserman and Fredsoe (1994) formula (solid line), the dashed line shows $c=0.2$. b) Comparison between the numerical results and van Rijn (2007) formula (solid lines, different colours corresponding to different sediment diameters increasing to the left). The dashed line corresponds to the best linear fit to the numerical data (equation 11). 

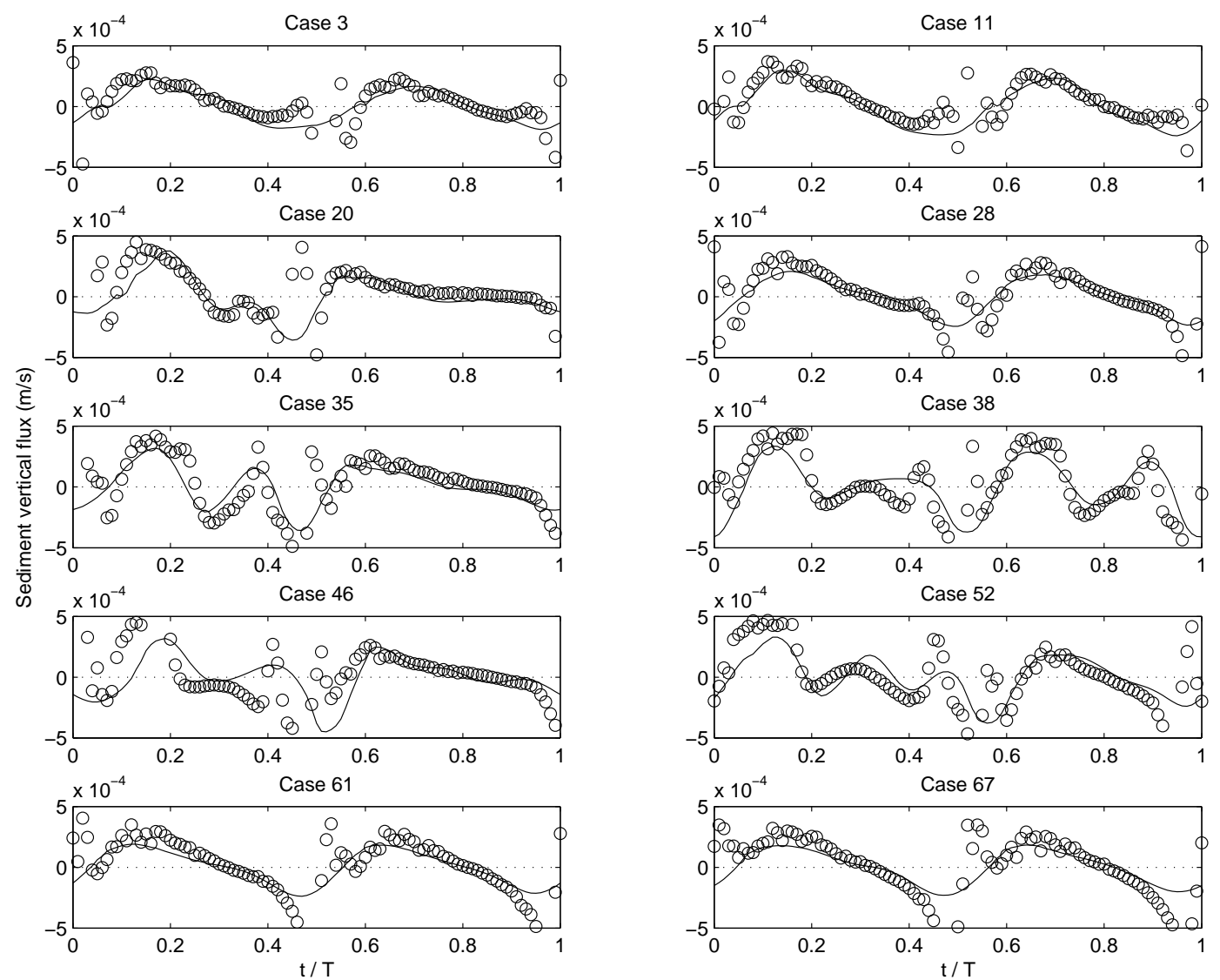

Figure 12: Examples of intra-wave net vertical sediment flux two diameters above the undisturbed bed: numerical results (circles) and parameterization with equation 12 (solid line). 


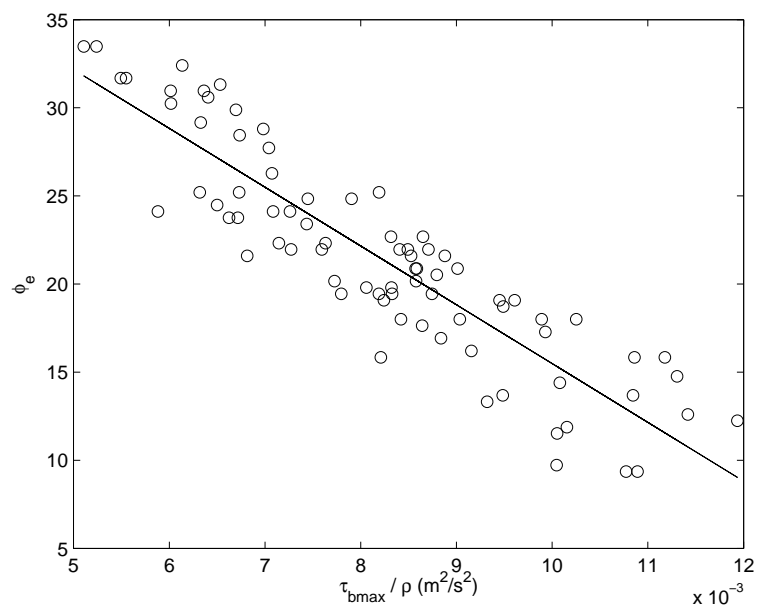

Figure 13: Phase lag of the vertical sediment flux with respect to the near-bed acceleration, numerical results (circles) and equation 13 (solid line). 